\title{
The COVID-19 pandemic and E-learning: challenges and opportunities from the perspective of students and instructors
}

\author{
Abdelsalam M. Maatuk ${ }^{1}$ (D) . Ebitisam K. Elberkawi ${ }^{1}$. Shadi Aljawarneh ${ }^{2}$. \\ Hasan Rashaideh ${ }^{3} \cdot$ Hadeel Alharbi $^{4}$
}

Accepted: 18 March 2021 / Published online: 3 May 2021

(c) The Author(s), under exclusive licence to Springer Science+Business Media, LLC, part of Springer Nature 2021

\begin{abstract}
The spread of COVID-19 poses a threat to humanity, as this pandemic has forced many global activities to close, including educational activities. To reduce the spread of the virus, education institutions have been forced to switch to e-learning using available educational platforms, despite the challenges facing this sudden transformation. In order to further explore the potentials challenges facing learning activities, the focus of this study is on e-learning from students' and instructor's perspectives on using and implementing e-learning systems in a public university during the COVID-19 pandemic. The study targets the society that includes students and teaching staff in the Information Technology (IT) faculty at the University of Benghazi. The descriptive-analytical approach was applied and the results were analyzed by statistical methods. Two types of questionnaires were designed and distributed, i.e., the student questionnaire and the instructor questionnaire. Four dimensions have been highlighted to reach the expected results, i.e., the extent of using e-learning during the COVID-19 pandemic, advantages, disadvantages and obstacles of implementing E-learning in the IT faculty. By analyzing the results, we achieved encouraging results that throw light on some of the issues, challenges and advantages of using e-learning systems instead of traditional education in higher education in general and during emergency periods.
\end{abstract}

Keywords Covid-19 $\cdot$ Pandemic $\cdot$ E-learning $\cdot$ Higher education $\cdot$ Information technology

Abdelsalam M. Maatuk

abdelsalam.maatuk@uob.edu.ly

Extended author information available on the last page of the article 


\section{Introduction}

The unexpected closure of educational institutions as a result of the emergence of COVID-19 prompted the authorities to suggest adopting alternatives to traditional learning methods in emergencies to ensure that students are not left without studying and to prevent the epidemic from spreading.

The formal learning system with the help of electronic resources is known as e-learning. Whereas teaching can be inside (or outside) the classrooms, the use of computer technology and the Internet is the main component of e-learning (Aboagye et al. (2020). The traditional educational methods were replaced by e-learning when the COVID-19 virus appeared because social gatherings in educational institutions are considered an opportunity for the virus to spread. E-learning is the best option available to ensure that epidemics do not spread, as it guarantees spatial distancing despite the challenges and studied figures, which indicate that students are less likely to benefit from this type of education (Lizcano et al. (2020).

Information and communication technologies (ICTs) offer unique educational and training opportunities as they improve teaching and learning, and innovation and creativity for people and organizations. Furthermore, the use of ICT can promote the development of an educational policy that encourages creative and innovative educational institution environments (Abdullah et al. 2019; Altawaty et al. 2020; Selim, 2007). Therefore, attention is given widely to efforts and experiences related to this type of education. This technology is commonly used by most universities in several developing countries. In an educational environment, there are lots of learning-related processes involved, and great amounts of potential rich data are generated in educational institutions continuously in order to extract knowledge from those data for a better understanding of learning-related processes (Aljawarneh, 2020; Lara et al. 2020; Lizcano et al. 2020).

E-learning is playing a vital role in the existing educational setting, as it changes the entire education system and becomes one of the greatest preferred topics for academics (Samir et al. 2014). It is defined as the use of diverse kinds of ICT and electronic devices in teaching (Gaebel et al. (2014). Most students today want to study online and graduate from universities and colleges around the world, but they cannot go anywhere because they reside in isolated places without good communication services.

Because of e-learning, participants can save time and effort for living in distant places from universities where they are registered, so, many scholars support online courses (Ms \& Toro, 2013).

Many users of e-learning platforms see that online learning helps ensure that e-learning can be easily managed, and the learner can easily access the teachers and teaching materials (Gautam, 2020; Mukhtar et al. 2020). It also helped reduce the effort and travel expenses and other expenses that accompany traditional learning. E-learning reduced significantly the administrative effort, preparation and lectures recording, attendance, and leaving classes. Teachers, as well as students, see that online learning methods encouraged pursuing lessons from 
anywhere and in difficult circumstances that prevent them from reaching universities and schools. The student becomes a self-directed learner and learns simultaneously and asynchronously at any time. However, there are many drawbacks of e-learning, the most important of which is getting knowledge only on a theoretical basis and when it comes to using everything that learners have learned without applied practical skills. The face-to-face learning experience is missing, which may interest many learners and educators. Other problems are related to the online assessments, which may be limited to objective questions. Issues related to the security of online learning programs and user reliability are among the challenges of e-learning in addition to other difficulties that are always related to the misuse of technology (Gautam, 2020; Mukhtar et al. 2020).

Web-based education, digital learning, interactive learning, computer-assisted teaching and internet-based learning are known as E-learning (Aljawarneh, 2020; Lara et al. 2020; Yengin et al. 2011). It is mainly a web-based education system that provides learners with information or expertise utilizing technology. The use of web-based technology for educational purposes has increased rapidly due to a drastic reduction in the cost of implementing these technologies. Nowadays, many universities have recognized the importance of E-learning as a core element of their learning system. Therefore, further research has been conducted to understand the difficulties, advantages, and challenges of e-learning in higher education. These issues have the potential to adversely affect instructors' quality in the delivery of educational material (Yengin et al. 2011).

Technology-based E-learning requires the use of the internet and other essential tools to generate educational materials, educate learners, and administer courses in an organization. E-learning is flexible when considering time, location, and health issues. It increases the effectiveness of knowledge and skills by enabling access to a massive amount of data, and enhances collaboration, and also strengthens learningsustaining relationships. Although e-learning can enhance the quality of education, there is an argument about making E-learning materials available, which leads to improving learning outcomes only for specific types of collective evaluation. However, e-learning may result in the heavy use of certain websites. Moreover, it cannot support domains that require practical studies. The main drawback of using e-learning is the absence of crucial personal interactions, not only between students and teachers but also among fellow students (Somayeh et al. 2016). Compared to developed countries, it was found that developing countries face many challenges in applying e-learning, including poor internet connection, insufficient knowledge about the use of information and communication technology, and weak content development (Aung \& Khaing, 2015). The provision of content such as video and advanced applications is still a new thing for many educators, even at the higher education level in developing countries (Aljawarneh, 2020; Lara et al. 2020; Lizcano et al. 2020).

This study aims to identify issues related to the use, advantages, disadvantages, and obstacles of e-learning programs in a public university by extrapolating the perspectives of students and educators who use this mode of learning in longlasting unusual circumstances. The research population consisted of students and faculty members at the Faculty of IT at the University of Benghazi. Two types of 
questionnaires have been distributed to students and instructors. To achieve the expected results, four dimensions are defined, i.e., the extent to which E-learning is used and the benefits, drawbacks, and obstacles to the implementation of E-learning by the Faculty of IT. The descriptive-analytical method is used in the statistical analysis of the results. By evaluating the results, we have obtained promising findings that demonstrate some of the higher education sector's problems, obstacles, and advantages of using the E-learning method. Students believe that based on the study's results, E-learning contributes to their learning. This reduces the instructor workload, however, and raises it for students. The teaching staff agrees that E-learning is beneficial in enhancing the skills of students, although it needs financial resources and the cost of implementing them is high. Despite the advantages of using E-learning, some of the obstacles to its implementation in Libya include the degradation of the Internet infrastructure that supports these education systems in Libya in general. The high cost of buying the electronic equipment needed and maintaining the equipment, which is unemployed.

The remainder of this paper is organized as follows. Section 2 gives some background and related work about E-learning. Section 3 describes the methodology. Statistical analysis is presented in Sect. 4. Section 5 explains the study outcomes. Finally, Sect. 6 discusses the conclusion of this work and provides some recommendations.

\section{Related work}

Several studies have addressed the opportunities and challenges associated with the transition to traditional learning instead of e-learning. One of the main reasons for faltering e-learning initiatives is the lack of well-preparedness for this experience.

A study that aims to examine student challenges about how to deal with e-learning in the outbreak of COVID-19 and to examine whether students are prepared to study online or not is presented in (Aboagye et al. 2020). The study concluded that a blended approach that combines traditional and e-teaching must be available for learners. Another study that aims to explore the e-learning process among students who are familiar with web-based technology to advance their self-study skills is described in (Radha et al. 2020). The study results show that e-learning has become popular among students in all educational institutions in the period of lockdown due to the COVID-19 pandemic.

A study that aims to investigate the characteristics, benefits, drawbacks and features that impact E-learning has been presented in (Ms \& Toro, 2013). Some of the demographic features such as behaviors and cultural background impact student education in the E-learning domain. Therefore, for lecturers to design educational activities to make learning more effective, they should understand these features. The study is applied to students in Lebanon and England to assist instructors to understand what scholars expect from the learning management systems.

Analyzing the effectiveness of E-learning for students at the university level has been introduced in (Ali et al. 2018). A questionnaire was applied to a sample of 700 students, $94.9 \%$ of them are utilizing different e-learning techniques and tools. To 
measure the reliability and internal consistency of the factors, Cronbach's alpha test is applied. To take out the variables and to calculate the factors loading in the study, the exploratory feature analysis is applied. The results demonstrate that students support that E-learning is easy to use, saves time, and affordable.

Various predictions of e-learning for educational purposes have been illustrated in (Samir et al. 2014). The study aims to show how to keep students motivated in e-learning. The evaluation of student motivations for online learning can be challenging because of the lack of face-to-face contact between learners and teachers. The study shows that one way to increase student's motivation is by allowing them to complete an online assessment form on motivation. The study suggests five research hypotheses to be inspected to identify which hypothesis should be accepted and which should not.

The strength of the relationship between students' motivation and e-learning is illustrated in (Harandi, 2015). Data was gathered from students at Tehran Alzahra University, and Pearson's correlation coefficient was utilized for data analysis. The outcomes of this study revealed that some points should be considered before using E-learning. However, this study was restricted to one culture, which can limit the generalization of its results.

The study described in (Oludare Jethro et al. 2012) showed that e-learning is a new atmosphere for scholars, as it illustrates how to make e-learning more effective in the educational field and the advantages of using e-learning. The outcome of the study showed that the students were willing to learn more with less social communication with other students or lecturers.

A study that aims to highlight and measure the four Critical Success Factors from student insights is described in (Selim, 2007). These factors are instructor and student characteristics, technology structure, and university support. The outcomes of the study showed that the instructor characteristics factor is the most critical one followed by IT infrastructure and university support in e-learning success. The least critical factor to the success of e-learning was student characteristics.

The work described in (GOYAL \& S., 2012) has tried to emphasize the importance of e-learning in modern teaching and illustrates its advantages and disadvantages. Also, the comparison with Instructor Led Training (ILT) and the probability of applying E-learning instead of old classroom teaching was discussed. In addition, the study showed the major drawbacks of ILT in institutions and how using E-learning can assist in overcoming these problems.

The purpose of the study in (Gaebel et al. 2014) is to conduct a survey on the varieties of E-learning organizations, skills, and their anticipations for the forthcoming. Blended and online learning are taken into account. Some of the questions related to intra-institutional management, arrangements and services, and quality assurance. The outcomes of the survey showed that from 38 diverse countries and systems, there are 249 organizations broadly conceived the same causes for the increasing use of e-learning.

The study in (Yengin et al. 2011) illustrated that the most vital role in the e-learning design outlook is online lecturers. As a result, considering the issues impacting lecturers' performance should be taken into the account. One of the features that impact the usability of the system and lecturers' presentation is satisfaction. The results showed, 
to produce a simple model called the "E-learning Success Model for Instructors' Satisfactions" that is related to public, logical and technical communications of instructors in the entire e-learning system, the features associated with teachers' satisfaction in e-learning systems have been examined.

The comparison between different E-learning tools in terms of their goals, benefits and drawbacks are presented in (Aljawarneh et al. 2010). The comparison assists in providing when to use each tool. The outcomes show that instructors and students prefer to use MOODLE over Blackboard in the e-learning environment. One of the major challenges that face the E-learning environment is security issues since security is not combined into the active learning development process.

The effect of e-learning at the Payame Noor University of Hamedan, Iran on the innovation and material awareness of chemistry students was examined in (Zare et al. 2016). The research used a control group's pre-test/post-test experimental design. Data analysis findings using the independent t-test showed significantly better scores on calculated variables, information and innovation for the experimental group. Consequently, E-learning is beneficial for the acquisition of knowledge and innovation among chemistry students, and that a larger chance for E-learning should be given for broader audiences.

A study in (Arkorful \& Abaidoo, 2015) aimed to explore the literature and provide the study with a theoretical context by reviewing some publications made by different academics and universities on the definition of E-learning, its use in education and learning in institutions of higher education. The general literature described the pros and cons of E-learning, which showed that it needs to be enforced in higher education for teachers, supervisors and students to experience the full advantages of acceptance and implementation.

Assessing the learning effectiveness of e-learning was studied in (Somayeh et al. 2016). This analysis study was conducted using the databases of Medline and CINAHL and the search engine of Google. The research used covered review articles and English language meta-analysis. 38 papers including journals, books, and websites are investigated and categorized from the results obtained. The general advantages of E-learning such as the promotion of learning and speed and process of learning due to individual needs were discussed. The study results indicated positive effects of E-learning on learning, so it is proposed that more use should be made of this education method, which needs the requisite grounds to be established.

It is important to focus on analyzing the learner and student characteristics and motivating students to ensure their involvement in e-learning. Also, it is necessary to focus on the impact and extent of teacher acceptance of e-learning. The age difference between the teachers and the students indicates that the teachers received most of their studies and teaching skills through traditional teaching and learning methods, which may make their acceptance of e-learning different from the student's acceptance of modern methods of e-learning and education in general. 


\section{The methodology}

The descriptive-analytical method was used for this study and the five-point Likertscale range was calculated based on (1) Strongly disagreed, (2) Disagree, (3) Neutral, (4) Agree, and (5) Strongly agree, with the analysis of results using a statistical application called the Statistical Package for the Social Sciences (SPSS).

\section{Study population}

The study targets the sample society that includes teaching staff and undergraduate students of all departments in the IT Faculty at the University of Benghazi.

\section{Study boundaries}

- Scientific restrictions: Assessment of the extent of application of E-learning in higher education.

- Administrative Field: Faculty of IT, University of Benghazi, Libya.

- Period: The Year of 2020.

- Human Resources: Teaching staff and students in the faculty.

\section{Study sample}

The study involves two types of questionnaires to be prepared and developed: one questionnaire for students and another for instructors. The following details were obtained after the questionnaires were randomly distributed and collected individually. The study sample was selected based on the awareness of the size of the population:

- Student Questionnaire: The total number of distributed questionnaires was 140 copies, without invalid copies, and 5 copies were missing. Therefore, the copies being analyzed are 135 .

- Teaching Staff Questionnaire: The total number of distributed questionnaires was 20 copies, while 20 legitimate copies were returned without invalid or missing copies.

Some of the demographic characteristics are shown in Table 1.

\section{Study dimensions}

The study has emphasized four dimensions to achieve the expected results as follows:

1. The extent of using E-learning in the Faculty of IT.

2. Advantages of E-learning. 
Table 1 Distribution of student study sample

\begin{tabular}{lll}
\hline Character name & Count & Percentage \\
\hline $\begin{array}{l}\text { 1. Gender } \\
\text { Male }\end{array}$ & 78 & \\
Female & 57 & $57.8 \%$ \\
2. Age & & $42.2 \%$ \\
$18-20$ & 65 & \\
$21-23$ & 35 & $48.1 \%$ \\
$24-26$ & 23 & $25.9 \%$ \\
Older & 12 & $17 \%$ \\
3. Semester & & $9 \%$ \\
$1-3$ & 68 & \\
$4-5$ & 23 & $50.4 \%$ \\
$6-8$ & 20 & $17 \%$ \\
Above & 24 & $14.8 \%$ \\
Total & 135 & $17.8 \%$ \\
\hline
\end{tabular}

3. Disadvantages of E-learning.

4. Obstacles to implementing E-learning.

\section{Statistical analysis}

\section{Data analysis}

The Means and Materiality statistical relations are used to analyze the results. By evaluating the findings, we gain crucial information based on these statistical relations according to the rank of inquiries as shown in Tables 2-3.

\section{The students' perspective}

The analysis of data as a statistical relationship regarding the perspective of the students is shown in Table 2 .

Dimension 1: the extent of using E-learning in IT faculty. Inquiries (6), (7) and (10) are of similar materiality and inquiry (6) is chosen because it has the lower standard deviation, which states that "E-learning technologies are used for scientific research purposes" with the materiality of $82.6 \%$ and a mean 4.13 , while inquiry number (7), which states "Search engines are used to obtain curriculum needs". However, inquiry (2), which states that "the Internet is available to students at the faculty" has the lowest materiality of $40 \%$ and a mean 2 .

Dimension 2: advantages of E-learning Inquiry number (1) states that "E-learning contributes to raising your educational level" has the highest materiality of $88.2 \%$ and a mean of 4.41. However, inquiry number (7), which states that "E-learning 


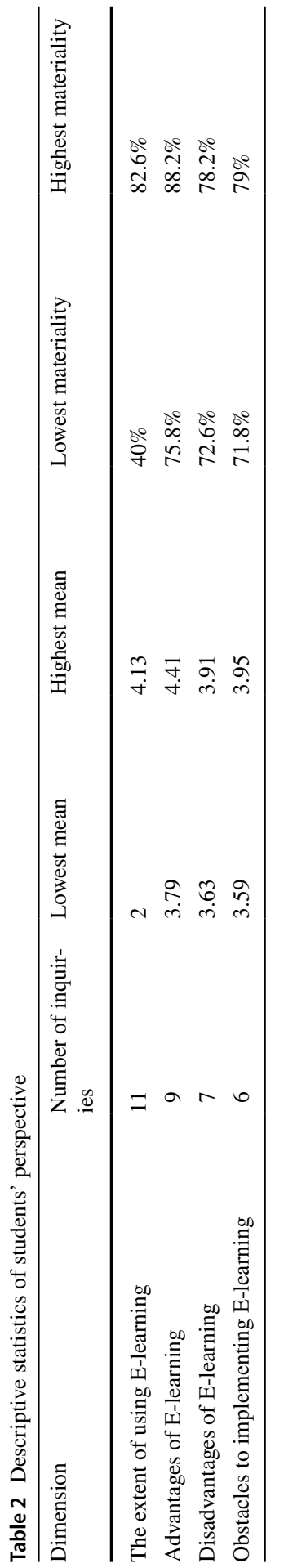




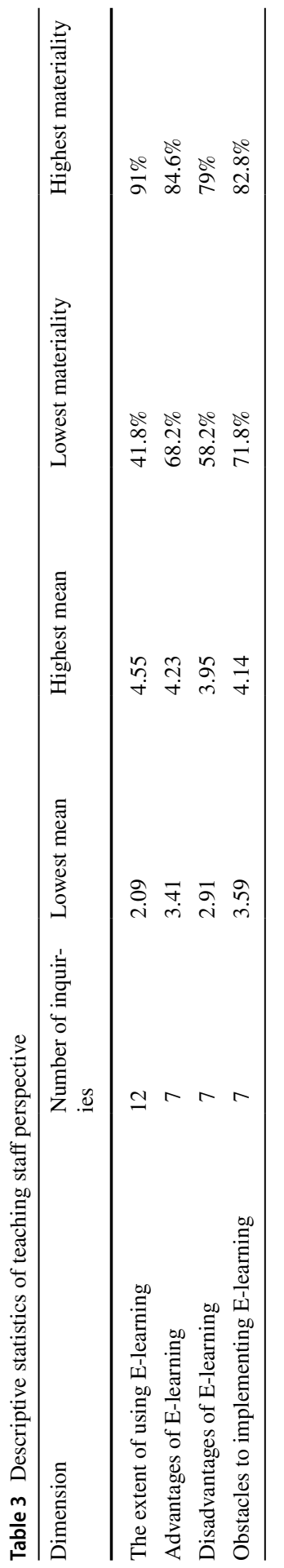


reduces the burden because learning becomes a conversation between teaching staff and students instead of traditional learning", has the lowest materiality of $75.8 \%$ and a mean of 3.79 .

Dimension 3: disadvantages of E-learning Inquiries (5) and (6) are of similar materiality and inquiry number (5) is chosen because it has the lower standard deviation, which states that "E-learning reduces the burden of teaching staff and increases the burden of students" with the materiality of $75.4 \%$ and a mean of 3.77 . Nevertheless, inquiry number (1), which states that "E-learning isolates you from the community by connecting you to your computer for long periods ", was the lowest materiality of $72.6 \%$ and a mean of 3.63 .

Dimension 4: obstacles to E-learning Inquiry number (3) states that "the lack of the Internet in the faculty to apply E-learning" has the highest materiality of 79\% and a mean of 3.95. Yet, inquiries (4) and (5) are of similar materiality and inquiry number (5) has been chosen as it has the lower standard deviation, which notes that "Lack of experience of students with E-learning techniques" with the materiality of $71.8 \%$ and a mean of 3.59 .

\section{Teaching staff perspective}

The analysis of data as a statistical relationship regarding the perspective of the teaching staff and the important analyzes of mean and materiality is given in Table 3

Dimension 1: the extent of using E-learning in IT faculty Inquiry number (10), which was about that "Use email to communicate with colleagues", has the highest materiality of $91 \%$ and a mean of 4.55 . However, inquiry number (2), which states that "internet accessible always available to teaching staff in the faculty", has the least materiality as $41.8 \%$ and the mean is 2.09 .

Dimension 2. advantages of E-learning Inquiry number (4) which states that "E-learning contributes to increasing students' skills in using computers" has the highest materiality of $84.6 \%$ and a mean of 4.23 . However, inquiry number (7), which states that "E-learning reduces the burden because learning becomes a conversation between teaching staff and students instead of traditional learning" with the lowest materiality of $68.2 \%$ and a mean of 3.41 .

Dimension 3: disadvantages of E-learning Inquiry number (6) which states that "E-learning needs financial capability compared to traditional education" has the maximum materiality of $79 \%$ and a mean of 3.95. Nevertheless, inquiry number (3), which reports that "students face a greater burden during the educational process while reducing the burden of teaching staff", has the lowest materiality of $58.2 \%$ and a mean of 2.91 . 
Table 4 Statistical tests (students' perspective)

\begin{tabular}{lcccl}
\hline Dimension & Mean & STDev & T-Test & $P$-value \\
\hline The extent of using E-learning & 3.44 & 0.590 & 8.733 & 0.00 \\
Advantages of E-learning & 4.13 & 0.574 & 22.86 & 0.00 \\
Disadvantages of E-learning & 3.78 & 0.705 & 12.786 & 0.00 \\
Obstacles to E-learning & 3.75 & 0.732 & 11.961 & 0.00 \\
\hline
\end{tabular}

Table 5 Statistical tests (Teaching staff perspective)

\begin{tabular}{lcccl}
\hline Dimension & Mean & STDev & T-Test & $P$-value \\
\hline The extent of using E-learning & 3.59 & 0.466 & 6.021 & 0.00 \\
Advantages of E-learning & 3.99 & 0.516 & 9.015 & 0.00 \\
Disadvantages of E-learning & 3.35 & 0.431 & 3.813 & 0.001 \\
Obstacles to E-learning & 3.82 & 0.594 & 6.505 & 0.00 \\
\hline
\end{tabular}

Dimension 4: obstacles to E-learning Inquiries (4) and (7) are of similar materiality and inquiry number (4) is chosen because it has the lower standard deviation, which states that "The lack of internet in the faculty to apply e-learning" with the materiality of $82.8 \%$ and a mean 4.14 . Yet, inquiries (3) and (6) are of similar materiality and inquiry (6) is chosen, which states that "E-learning needs high costs" has the lowest materiality of $71.8 \%$ and a mean of 3.59 .

\section{Results and discussion}

\section{Students' perspective}

As shown in Table 4, we found the T-Test value $=8.733$ and the $P$-Value $=0.00$ to the extent of using E-learning during the pandemic. T-Test value $=22.86$ and $P$-Value $=0.00$ for the advantages of E-learning. The T-Test value $=12.786$ and $P$-Value $=0.00$ for the drawbacks of E-learning. The obstacles to E-learning in the last dimension are the T-Test value $=11.961$ and the $P$-Value $=0.00$. Accordingly, all T-Test values are greater than the T table value $=1.96$. On the other side, all $P$-Values are smaller than the level of significance $=0.05$. Thus, in each dimension of the four dimensions of the sample, there were statistically significant differences from the student's perspectives.

\section{Teaching staff perspective}

As shown in Table 5, the extent, to which E-learning is used are T-Test $=6.021$ and $P$-Value $=0.00$, the advantages of E-learning are T-Test $=9.015$ and $P$-Value $=0.00$, the disadvantages of E-learning are T-Test $=3.813$ and $P$-Value $=0.001$, and the obstacles to E-learning are T-Test $=6.505$ and $P$-Value $=0.00$ respectively. Depending on the T-Test values are higher than the $\mathrm{T}$ table value $=1.96, P$-Values are less 
than the level of significance $=0.05$. There were statistically significant differences from the teaching staff perspective in each dimension of the study's four dimensions.

The data analysis of the four dimensions is summarized as follows:

1. The extent of the use of e-learning: the findings indicate that the student's approval of the use of e-learning and the teaching staff's viewpoint is (Agreement), where the mean are (3.44) and (3.59) respectively.

2. The advantages of e-learning: the results consider this dimension indicates the approval of the advantages of e-learning from the perspective of students and teaching staff was (Agreement), where the mean of the perspective of students was (4.13) and the mean of the perspective of the teaching staff was (3.99).

3. The dimension that constituted the disadvantages of e-learning: This indicates that the student's acceptance drawbacks of e-learning are (Agreement) of the mean (3.78) and the teaching staff's opinion was (Undecided) of the mean (3.35).

4. The factor defining obstacles to e-learning indicates that there were acceptance obstacles for e-learning from the perspective of both students and teaching staff (i.e., Agreement), where the mean was (3.75) and (3.82).

\section{A comparison between the two perspectives}

As shown in Fig. 1, it is noticeable that the viewpoint of both the teaching staff and the students in all four dimensions of the study is identical. This demonstrates that they are almost standardized, with little variation in the third dimension of the data considered for the disadvantages of e-learning during the Covid-19 pandemic. This factor achieves the agreement from the teaching staff's perspective and is undecided from the students' perspective to achieve the agreement as to the outcomes.

\section{A description of the dimensions of the sample}
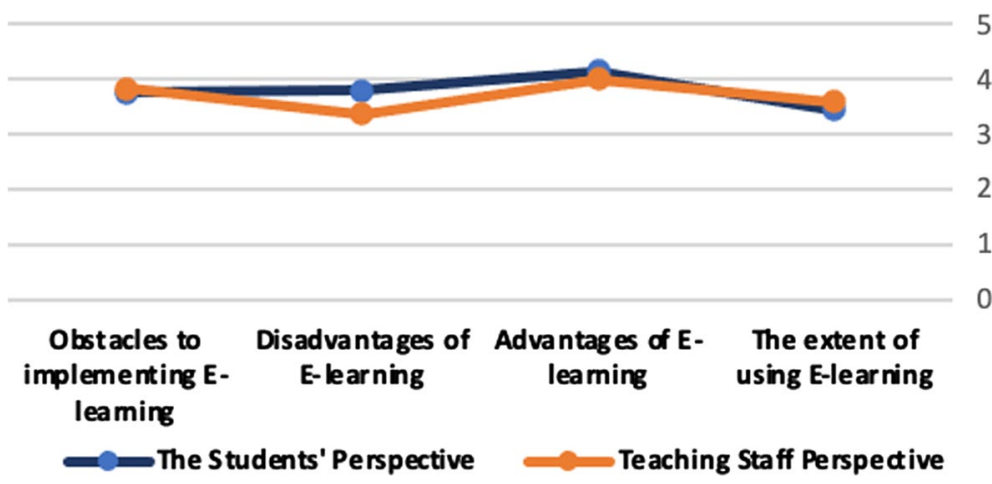

Fig. 1 A comparison of students' and teaching staff' perspectives 


\section{The study outcomes}

The study outcomes could be summaries as follows:

\section{Findings based on students' perspective}

- The students believe that e-learning is used and that one of the most significant uses is a replica of the scientific method learned on electronic/multimedia forms.

- The students agree that e-learning is useful and that it helps them to be safe and improved their academic standards.

- The students claim that the introduction of e-learning is difficult and that the low-quality of internet services is the biggest obstacle to its application.

- The students demonstrate that there are limitations to e-learning and that the biggest downside is that it decreases the workload for teaching staff and raises the pressure on students.

\section{Findings based on teaching staff perspective}

- The teaching staff believes that e-learning is beneficial and that helping to develop students' technological skills is one of the most critical positive elements.

- The teaching staff agrees that the use of e-learning is common and that the possession of faculty members via e-mail and other e-services is the most significant use.

- The teaching staff agrees that there are barriers to the introduction of e-learning and that the high cost of its implementation is one of the main difficulties.

- The teaching staff accepts that e-learning has disadvantages and that the biggest downside is that, relative to traditional learning, it requires financial support.

\section{Pedagogical aspects}

Any e-learning strategy follows one of the commonly known learning theories, i.e., behaviorism, cognitivism, or constructivism (Mödritscher, 2006). Furthermore, each didactic strategy has a more or less strong impact on the factors that influence the learning process and the self-assessment of the characteristics of the learner. Therefore, based on what has been achieved through the opinions of teaching staff and students, we found that the certain characteristics of the learner, in particular, the motivation need to be analyzed. It is also necessary, as an appropriate pedagogical step, to choose an e-learning strategy that suits the characteristics of students and the electronic environment they are living in nowadays. 


\section{Conclusion and recommendations}

This study aims to identify the major issues and challenges by extrapolating the opinions of students and faculty instructors on the use of e-learning systems in a public university during the Covid-19 pandemic. The study society sample consists of students and faculty members at the Faculty of IT, University of Benghazi. The descriptive-analytical approach has been applied with statistical analysis of the results. Two types of questionnaires have been distributed for students and instructors. Four dimensions have been determined to reach the expected results, i.e., the extent to which e-learning is used and the advantages, disadvantages and obstacles to the implementation of E-learning in the Faculty of IT. Learning and teaching in an electronic environment still provide many advantages, including, reducing expenses and affords. It was also a successful alternative for many students to return to study in educational institutions during the spread of the Covid19 virus, despite facing many issues and challenges. By analyzing the results, we have achieved encouraging results to highlight some of the issues, challenges and benefits of using the e-learning system in the higher education sector.

Issues such as technical and financial support, training, improved working conditions, technological background, skills, copyright protections and professional development are always important in the implementation of e-learning in public universities. Based on the study results, students believe that e-learning contributes to their learning. However, it reduces the workload on faculty and increases it on students. The main obstacle to e-learning is the low-quality of Internet services in Libya during the pandemic period. Faculty members agree that e-learning is useful in increasing students' computer skills, although it requires significant financial resources. We can claim that it is important to highlight many of the recommendations, which could have a positive impact on the possibility of implementing e-learning. The university has to provide internet service to students and teaching staff members with enough computer devices to apply e-learning. A modern electronic library and dedicated classrooms with all types of equipment and tools needed are also necessary to apply e-learning instead of coming to the main campus. Conducting online training and seminars regularly is important, for teaching staff, in particular, to support the application of e-learning, in addition to constant attention to IT infrastructure and periodic maintenance of computers and supporting equipment. In addition to all of this, the role and importance of focusing on many things related to the characteristics of the learner, such as the characteristics of the student's background knowledge and how to motivate the students as one of the pedagogical impacts.

\section{References}

Abdullah, F. M., Mohammed, A. A., Maatuk, A. M. and Elberkawi, E. K.: Application of electronic management system in governmental institutions: An empirical study on the Libyan civil registration. In Proceedings of 2nd International Conference on Data Science, E-Learning and Information 
Systems (DATA '19). Dubai, UAE-December 02 - 05, 2019. ACM: New York, NY, USA, Article No. 19. Doi: https://doi.org/10.1145/3368691.3368710

Aboagye, E., Yawson, J. A., \& Appiah, K. N. (2020). COVID-19 and E-learning: The Challenges of Students in Tertiary Institutions. Social Education Research, 2(1), 1-8. https://doi.org/10.37256/ser. 212021422.

Ali, M., Khaled Hossain, S. M., \& Ahmed, T. (2018). Effectiveness of E-learning for university students: Evidence from Bangladesh. Asian Journal of Empirical Research., 8(10), 352-360. https://doi.org/ 10.18488/journal.1007/2018.8.10/1007.10.352.360.

Aljawarneh, S. A. (2020). Reviewing and exploring innovative ubiquitous learning tools in higher education. Journal of Computing in Higher Education, 32, 57-73. https://doi.org/10.1007/ s12528-019-09207-0.

Aljawarneh, S., Muhsin, Z., Nsour, A., Alkhateeb, F. and AlMaghayreh, E. (2010). E-learning tools and technologies in education. In A Perspective. LINC Proceedings

Aljawarneh, S., Maatuk, A. and Ali, A. 2012. Security Issues in Cloud Computing: A Perspective, In The Proceedings of the 9th International Conference on Electronics, Computer and Computation (ICECCO'12), Ankara, Turkey.

Altawaty, J. A., Benismail, A. and Maatuk, A. M.. 2020. Experts' opinion on the IT skills training needs among healthcare workers. In Proceedigs of International Conference on Engineering and Information Management Systems 2020 (ICEMIS'20), Almaty, Kazakhstan, September 14-16. DOI: https:// doi.org/10.1145/3410352.3410790

Arkorful, V., \& Abaidoo, N. (2015). The role of e-learning, advantages and disadvantages of its adoption in higher education. International Journal of Instructional Technology and Distance Learning., 12(1), 29-42.

Aung TN, Khaing SS. Challenges of implementing e-learning in developing countries: A review. In International Conference on Genetic and Evolutionary Computing. Springer, Cham; 2015. pp. 405-411.

Benefits, E.-L. 2016. Nischal Guragain. February (2016).

Eseroghene, U., \& Ahmad, A. (2018). The impact of E-learning on academic performance: Preliminary examination of King Khalid University. International Journal of Academic Research in Progressive Education and Development., 7(71), 83-96. https://doi.org/10.6007/IJARPED/v7-i1/3903.

Gaebel, M., Kupriyanova, V., Morais, R. and Colucci, E. 2014. E-learning in European Higher Education Institutions November 2014 Results of a mapping survey conducted in October-December 2013 Michael Gaebel, Veronika Kupriyanova, Rita Morais, Elizabeth Colucci.

Gaur, P. (2018). Research trends in E-learning Poonam Gaur. Shanlax International Journal of Commerce., 6(1), 36-39. https://doi.org/10.5281/zenodo.1438182.

Gautam, P. 2020. Advantages and disadvantages of online learning. In E-Learning Industry.

Goyal, S. . (2012). E-learning: Future of education. Journal of Education and Learning (EduLearn)., 6(4), 239. https://doi.org/10.11591/edulearn.v6i4.168.

Harandi, S. R. (2015). Effects of e-learning on Students' Motivation. Procedia-Social and Behavioral Sciences., 181, 423-430. https://doi.org/10.1016/j.sbspro.2015.04.905.

Lara, J. A., Aljawarneh, S., \& Pamplona, S. (2020). Special issue on the current trends in E-learning Assessment. Journal of Computing in Higher Education, 32, 1-8. https://doi.org/10.1007/ s12528-019-09235-w.

Lizcano, D., Lara, J. A., White, B., et al. (2020). Blockchain-based approach to create a model of trust in open and ubiquitous higher education. Journal of Computing in Higher Education, 32, 109-134. https://doi.org/10.1007/s12528-019-09209-y.

Mödritscher, F. (2006). The Impact of an E-Learning Strategy on Pedagogical Aspects. International journal of instructional technology and distance learning, 3(3), 85-98.

Mukhtar, K., Javed, K., Arooj, M., Sethi A. Advantages, limitations and recommendations for online learning during COVID-19 pandemic era. 2020;36 (COVID19-S4): COVID19-S27-S31. Doi: https://doi.org/https://doi.org/10.12669/pjms.36.COVID19-S4.2785

Ms, P., \& Toro, U. (2013). A review of literature on knowledge management using ICT. Higher Education., 4(1), 62-67.

Oludare Jethro, O., Moradeke Grace, A., \& Kolawole Thomas, A. (2012). E-learning and Its Effects on Teaching and Learning in a Global Age. International Journal of Academic Research in Business and Social Sciences., 2(1), 2222-6990.

Radha, R., Mahalakshmi, K., Sathish, V., \& Saravanakumar, A. R. (2020). E-learning during lockdown of Covid-19 pandemic: A Global Perspective. International Journal of Control and Automation, 13(4), 1088-1099. 
Samir, M., El-Seoud, A., Taj-Eddin, I. A. T. F., Seddiek, N., El-Khouly, M. M., \& Nosseir, A. (2014). E-learning and Students' Motivation: A Research Study on the Effect of E-learning on Higher Education. International Journal of Emerging Technologies in Learning., 9(4), 20-26. https://doi.org/ 10.3991/ijet.v9i4.3465.

Selim, H. M. (2007). E-learning critical success factors: An exploratory investigation of student perceptions. International Journal of Technology Marketing., 2(2), 157. https://doi.org/10.1504/ijtmkt. 2007.014791.

Somayeh, M., Dehghani, M., Mozaffari, F., Ghasemnegad, S.M., Hakimi, H. and Samaneh, B. 2016. The effectiveness of E-learning in learning : A review of the literature Ph.D. of Nursing, Instructor, Department of nursing, Lahijan Branch, Islamic Azad University, Instructor, Department of Operating Room, Faculty of Medical Sciences, Birjand Un. International Journal of Medical Research \& Health Sciences. 5(2): 86-91.

Yengin, I., Karahoca, A., \& Karahoca, D. (2011). An E-learning success model for instructors' satisfaction in the perspective of interaction and usability outcomes. Procedia Computer Science., 3(2011), 1396-1403. https://doi.org/10.1016/j.procs.2011.01.021.

Zare, M., Sarikhani, R., Salari, M., \& Mansouri, V. (2016). The impact of E-learning on university students' academic achievement and creativity. Journal of Technical Education and Training., 8(1), 25-33.

Publisher's Note Springer Nature remains neutral with regard to jurisdictional claims in published maps and institutional affiliations.

Abdelsalam M. Maatuk is a professor, Software Engineering, at Benghazi University, Libya. He received his B.Sc. degree in Computer Science from Benghazi University, Libya, in 1995, and received his M.Sc. and Ph.D. degrees in 2004 and 2009, respectively from Northumbria University, UK. Dr. Maatuk returned to Omar Al Mukhtar University in Nov. 2009 as a lecturer. Dr. Maatuk joined Benghazi University in Aug. 2014, as an assistant professor in the Faculty of IT. He was appointed as Vice Dean of IT Faculty, Benghazi University in July 2015 to April 2019. Since May 2019, he is the Dean of IT Faculty, Benghazi University. Dr. Maatuk has published several articles in journals and conferences in the field of database systems and software engineering. His primary work and research interest spread over several research fields, e.g., object-based databases, database reengineering and software engineering.

Ebitisam K. Elberkawi is currently a lecturer in the Faculty of IT, University of Benghazi where she has been a faculty member since 2013. She received BSc in software engineering from Benghazi University and an MSc from the Academy of high studies, Libya in June 2010. From 2015-2018 she was the head of the information systems department at the IT Faculty, University of Benghazi. She has many publications and is presently workings on many more papers.

Shadi Aljawarneh is a professor, Software Engineering, at the Jordan University of Science and Technology, Jordan. He holds a BSc degree in Computer Science from Jordan Yarmouk University, an MSc degree in Information Technology from Western Sydney University, and a Ph.D. in Software Engineering from Northumbria University-England. His research is centered on software engineering, web and network security, elearning, machine learning, cloud computing and ICT fields. Aljawarneh has presented at and been on the organizing committees for a number of international conferences and is a board member of the International Community for ACM, Jordan ACM Chapter, ACS, and IEEE. Multiple papers have been selected as "Best Papers" in conferences and journals. He is also the Associate Editor for IEEE ACCESS and Electrical and Computer Engineering.

Hasan Rashaideh is an associate professor, Computer Science, at Al-Balqa Applied University, Jordan. He received his BSc and MSc degrees in computer science and information technology from Yarmouk University in 1999 and 2002 respectively. In 2008 he obtained his Ph.D. degree in computer science from Saint Petersburg Electrotechnical State University-Russian Federation. Then, he joined the department of computer science at Prince Abdullah Bin Ghazi Faculty of ICT / Al-Balqa Applied University-Jordan as an assistant professor. He was appointed as Head of the department from July 2015 to July 2018. His research interests include machine learning, image processing, and computer vision, information retrieval, and optimization. 
Hadeel Alharbi is an assistant professor, Computer Science at Hail University. She is head department for computer science and software engineering in the female branch, Hail University, Saudi Arabia. Her research interests include e-learning, recommendation systems, and information retrieval.

\section{Authors and Affiliations}

\section{Abdelsalam M. Maatuk ${ }^{1}$ (D) Ebitisam K. Elberkawi ${ }^{1} \cdot$ Shadi Aljawarneh $^{2}$. Hasan Rashaideh ${ }^{3}$. Hadeel Alharbi ${ }^{4}$}

Ebitisam K. Elberkawi

basma.elberkawi@uob.edu.ly

Shadi Aljawarneh

saaljawarneh@just.edu.jo

Hasan Rashaideh

rashaideh@bau.edu.jo

Hadeel Alharbi

h.alharbe@uoh.edu.jo

1 Faculty of Information Technology, Benghazi University, Benghazi, Libya

2 Faculty of Computer and Information Technology, Irbid, Jordan

3 Department of Computer Science, Prince Abdullah Ben Ghazi Faculty of Information Technology and Communication Technology, Al-Balqa Applied University, Salt 19117, Jordan

4 Computer Science, Ha'il University, Ha'il, Saudi Arabia 